\title{
Artelogie
}

artelogie Recherche sur les arts, le patrimoine et la littérature de l'Amérique latine

$6 \mid 2014$

Horizons et dispositifs des arts plastiques des pays du Río de la Plata (XXe siècle)

\section{Entre Buenos Aires y Montevideo, la circulación del grabado de Antonio Berni en los años sesenta}

Silvia Dolinko

\section{(2) OpenEdition \\ Journals}

Edición electrónica

URL: http://journals.openedition.org/artelogie/1338

DOI: 10.4000/artelogie.1338

ISSN: $2115-6395$

Editor

Association ESCAL

Referencia electrónica

Silvia Dolinko, «Entre Buenos Aires y Montevideo, la circulación del grabado de Antonio Berni en los años sesenta », Artelogie [En línea], 6 | 2014, Publicado el 24 junio 2014, consultado el 06 mayo 2019 URL : http://journals.openedition.org/artelogie/1338; DOI : 10.4000/artelogie.1338

Este documento fue generado automáticamente el 6 mayo 2019.

Association ESCAL 


\title{
Entre Buenos Aires y Montevideo, la circulación del grabado de Antonio Berni en los años sesenta
}

\author{
Silvia Dolinko
}

Cuando un artista llega a tener 50 años su estilo
está generalmente fijado, lo que significa adopción
de los supuestos para trabajar en la segunda parte
de su vida. Por eso sorprende el "cambio" ocurrido
hace aproximadamente cinco años en el modo
como crea Antonio Berni. Cómo no plantear
entonces, abiertamente el caso si a consecuencia
del cambio obtuvo uno de los grandes premios en
la Bienal de Venecia de 1962.

Estas palabras, reproducidas en las páginas del periódico montevideano El País en su edición del 11 de julio de 1966, correspondían a Jorge Romero Brest; "Antonio Berni expone en el Instituto General Electric" era el titular de la breve nota. ${ }^{1}$ La versión original del texto correspondía a la introducción del catálogo de la muestra retrospectiva de Berni que tuviera lugar en 1965 en las salas del Centro de Artes Visuales del Instituto Torcuato Di Tella (CAV-ITDT) de Buenos Aires, donde el crítico de arte y gestor argentino se desempeñaba como director. Esas mismas palabras eran retomadas como parte del material de difusión y prensa de la exposición de Berni en el Instituto General Electric (IGE) de Montevideo. No sólo circulaban los nombres y las imágenes a ambas márgenes del Río de la Plata, sino también las palabras.

2 Como señalaba Romero Brest, la obtención del Gran Premio en Grabado y Dibujo en la XXXI ${ }^{\circ}$ Biennale veneciana había implicado un cambio rotundo en la carrera del artista argentino. A partir de esa instancia, sus obras se presentaron a lo largo de los años sesenta especialmente entre Buenos Aires y París (PLANTE, 2013), pero también en otras ciudades de todo el mundo (PACHECO, 1999 : 262-270). Si en la muestra en el ITDT de Buenos Aires se expusieron obras diversas, lo que prevaleció en las demás presentaciones 
fue su producción gráfica contemporánea: una obra impactante, renovadora y consagrada, a la vez que múltiple, de formato más reducido que las pinturas-collage y más fácilmente transportable. Las estampas sobre el personaje de Ramona Montiel, sus amigos y las escenas de su agitada vida se mostraban en distintos puntos del planisferio.

El presente artículo se propone dar cuenta de la circulación del nuevo grabado de Antonio Berni a partir de su consagración en la Bienal de Venecia de 1962, centrándose en el caso de su presentación en el IGE de Montevideo y su vinculación con el ITDT. Se apunta así a poder dar cuenta de la inscripción de la obra del artista argentino en la trama institucional modernizadora rioplatense de los años sesenta. ${ }^{2}$ La inclusión de una exposición de Berni introducía un matiz diferencial en el programa de ambos espacios asociados a la vanguardia, brindando una visibilidad particular a sus exploraciones contemporáneas con el xilocollage-relieve, a la vez que destacaba las posibilidades de la circulación múltiple de la obra gráfica.

Si el gran premio de la Bienal de Venecia de 1962 no se hubiese enfocado súbitamente sobre la obra y la personalidad de Berni, acaso la fama de su trabajo hubiera quedado limitada a algunos países de Latinoamérica, y en especial [a la] Argentina. ${ }^{3}$

El 16 de junio de 1962 Berni obtuvo el Gran Premio en Grabado y Dibujo en la XXXIº Bienal de Venecia. Esta instancia, central para la historia del arte argentino, también resulta clave para comprender la propia redefinición de la carrera del artista. En momentos de gran impulso a los proyectos de internacionalización de la plástica argentina (GIUNTA, 2001) en el que los premios implicaban una fundamental validación simbólica, este logro resultó a la vez una vía para la jerarquización del arte nacional : se trató de la mayor recompensa lograda por un artista argentino hasta ese momento, obtenida en el más relevante certamen internacional.

5 La exploración de Berni en torno a las posibilidades de la gráfica se inscribió en un momento de intensa renovación de esta práctica: "la estampa estaba de moda" (GHEERBRANDT, 1958:53). En la Argentina, a partir de diversos cambios socioculturales y replanteos en el campo artístico, había comenzado un proceso de experimentación con el grabado desde fines de los años cincuenta. Es en este marco que se inscribe el trabajo gráfico de Berni, en donde prosigue su histórica opción por la figuración social imbricada con el collage como recurso actualizado. Berni incluía en su nueva obra objetos de desecho a los que les otorgaba un sentido narrativo al vincularlos a la historia representada. En el caso de Juanito Laguna, el niño pobre de "villa miseria", Berni sostenía su relato sobre el personaje -y, a través de él, sobre los límites del proyecto desarrollista- a partir del uso de materiales pobres como chatarra o madera corroída.

La obra que Berni presentó en la Biennale constó de cinco tintas de la serie Pampa y cielo y un conjunto sobre Juanito que incluía diez pinturas-collage y cinco xilografías de grandes dimensiones, tres de ellas con collage. Frente a los lineamientos del informalismo y la abstracción gestual de los jóvenes pintores también integrantes del envío argentino (Rómulo Macció, Mario Pucciarelli, Kazuya Sakai y Clorindo Testa), Berni parecía el candidato menos pensado para representar al nuevo arte argentino promovido desde las estrategias modernizadoras contemporáneas. Particularmente, Jorge Romero Brest crítico de arte y director del Museo Nacional de Bellas Artes-, quien actuó como miembro del jurado internacional en esa edición de la Bienal, no brindaba especial consideración a la figuración social del artista (DOLINKO, 2005). Sin embargo, el conjunto sí llamó la atención de los otros miembros del jurado internacional; como recordara Berni, "se vio 
como algo revulsivo, no ya por el contenido solamente, sino por la intención expresiva [... ] lo que el jurado vio y distinguió fue el planteo innovador y original, las justas equivalencias estéticas entre el tema y su realización" (VIÑALS, 1976: 89). El conjunto de Juanito Laguna era una de las excepciones figurativas a la regla abstracta del certamen (RAGON, 1962 b: 33).

El mayor impacto de las xilografías premiadas estaba dado por la elección de unos materiales y un formato insólitos para el canon de la gráfica. En momentos en que se reactualizaban las lecturas sobre el linaje vanguardista del collage, Berni incorporaba este recurso a la histórica xilografía: entre la tradición y la experimentación, su imbricación entre grabado en madera y materiales bastos resultaba un novedoso cruce entre el arte "alto" y los materiales "bajos" (DOLINKO, 2012).

8 Si esta obra implicaba una fuerte apuesta por lo experimental desde el punto de vista del procedimiento, Berni presentaba a nivel discursivo una relectura de la tradición del grabado social local por su elección iconográfica. A diferencia de las pinturas-collage de esta serie, situadas en un marco urbano y fabril, las xilografías de Juanito Laguna se despliegan con el telón de fondo del puerto de Buenos Aires : no es sino en el Riachuelo donde transcurren los baños y la pesca del niño. Con esta elección del tópico portuario, Berni se inscribía en una genealogía que incluía imágenes de los Artistas del pueblo José Arato, Guillermo Facio Hebequer y Adolfo Bellocq, y la de otros artistas gráficos como Mario Cecconi o Víctor Rebuffo. Berni también releía en clave contemporánea el tópico del niño que transita los basurales en busca de su sustento, tal como lo había representado Abraham Vigo en los treinta con Pibes de la Quema o el rosarino Juan Grela en los cuarenta con sus Juntadores en las Colinas de la basurita (GHILIONI y TAVERNA IRIGOYEN, 2008:82-90).

9 Así, partiendo de una tradición iconográfica del grabado en la Argentina y de una resolución técnica que conmocionaba la convención xilográfica, su desarrollo de la imagen del niño pobre le valió su consagración internacional. Su potente imagen sustentada por un procedimiento original y llamativo fue la carta fuerte en juego para su valoración. Con su intervención sobre la xilografía, Berni se afirmaba en un terreno que hasta entonces no había resultado central en su carrera pero que, gracias a su validación en la mayor competencia artística mundial, lo posicionaba en un lugar privilegiado en esos tiempos de gran visibilidad de la disciplina. Así, se puede sostener que fue a instancias del éxito en Venecia que Berni intensificó en los siguientes años su indagación sobre las posibilidades del grabado.

Su siguiente personaje, Ramona Montiel, quien de inocente niña y joven costurera deviene en prostituta, fue desplegado especialmente a través del xilocollage ; con el uso de elementos de consumo masivo resemantizados en la imagen, la saga de Ramona apunta a dar cuerpo a un cuerpo a ser consumido por los representantes del establishment local: el coronel, el marino, el burgués y el embajador son los poderosos "amigos" o protectores de la mujer ; sus figuras, destacadas por el leve relieve agregado al xilocollage.

11 Si el artista había recurrido a chatarra y maderas para plasmar el entorno portuario de Juanito, ahora ampliaba su arsenal de recursos. Manteles de plástico que imitaban encaje -un popular objeto contemporáneo que simulaba o traducía a un soporte barato y de nula calidad una cierta idea de refinamiento- componían las ropas de la prostituta, junto con botones recargados, recortes de metal perforado con máquinas industriales o piezas de mecano. Mientras que esos elementos respondían al repertorio de materiales de la sociedad de consumo internacional, la vinculación localista estaba dada en el uso 
referencial de las imágenes : la alusión a la "costurerita que dio el mal paso" de Evaristo Carriego en Ramona costurera o la presencia de íconos rioplatenses como Carlos Gardel incluido en Ramona vive su vida (donde el título de Berni se asociaba a la contemporánea película de Jean Luc Godard, Vivre sa vie) y luego retomado en diversas versiones de Ramona y Gardel. También en este caso, la narración de Berni se inscribía en una genealogía de imágenes de prostitutas en el grabado argentino desde los años veinte. Sin embargo, mientras que en esas obras anteriores se presentaba a la prostitución como un mal social, el tema deviene en los grabados de Berni como ironía sobre los "pilares" de la sociedad nacional, que aparecen caricaturizados (DOLINKO, 2012: 219-226).

La presentación de Ramona Montiel tuvo lugar en París, en la Galerie du Passeur, en mayo de 1963; pocos meses después, se exhibiría en el Museo de Arte Moderno de Buenos Aires. A partir de ese momento, esas estampas de Berni circularon en distintos espacios, incluyendo al centro de la vanguardia argentina : el Di Tella.

Es uno de los artistas que goza de mayor prestigio en el país y en el extranjero [...]. En 1965 realizó una exposición retrospectiva en el Instituto Torcuato Di Tella, Buenos Aires, que consolidó su prestigio.

En cuanto al carácter de su pintura, hacia los años 30 era surrealista, aunque de manera no ortodoxa; pero después se volcó al neorrealismo socialista, siendo durante varias décadas el representante más conspicuo de dicha tendencia [...] Finalmente, sorprendió con un nuevo cambio y radical, en 1961, al exponer una serie de grandes cuadros-collages, en los que relata la historia de un personaje creado por él, Juanito Laguna, después fue Ramona Montiel. Conservaba en ellos la postura neorrealista, pero empleando los medios de expresión que caracterizan a la pintura europea abstracta.

El viraje insólito hizo que se lo considerara desde un nuevo ángulo universalista. Y no sólo se destacó en la pintura, sino muy especialmente en el grabado, con los mismos personajes populares, innovando en la técnica para hacerlos. ${ }^{4}$

13 Creada como entidad de bien público sin fines de lucro y vinculada al núcleo de la familia Di Tella, poderosa empresa industrial argentina, el ITDT inició sus actividades en agosto de 1960 en una oficina del Museo Nacional de Bellas Artes, dirigido entonces por Romero Brest. A partir de 1963, éste pasó a desempeñarse formalmente como director del Centro de Artes Visuales del Di Tella.

Entre 1963 y 1970, los tres Centros de Arte del ITDT ocuparon un edificio de la céntrica calle Florida. Esta arteria de la ciudad de Buenos Aires era un escenario privilegiado para la vanguardia artística y el mercado de arte porteño desde principios del siglo XX, y conocido en los años sesenta como la "manzana loca", ya que en ese espacio se ubicaban distintos referentes de la renovación intelectual : la Facultad de Filosofía y Letras de la Universidad de Buenos Aires, cines, teatros, cafés, librerías y espacios de reunión y discusión. El Di Tella, sin dudas, fue epicentro de ese ámbito de efervescencia cultural (KING, 1985 ; GIUNTA, 2001 ; KATZENSTEIN y CIPPOLINI, 2011 ; PINTA, 2013). Además de los aportes de la familia Di Tella, el Instituto contó a lo largo de los años sesenta con subsidios de la Ford Foundation y la Rockefeller Foundation; la recepción de estos recursos financieros fue uno de los argumentos de mayor peso al momento del enfrentamiento con la institución por parte de los artistas más radicalizados en términos políticos a fines de la década (LONGONI y MESTMAN, 2010).

Aunque las posiciones estéticas e ideológicas de Berni y Romero Brest resultaban enfrentadas, la obra del artista conllevaba entonces la suficiente actualidad como para ser destacada en ese espacio asociado al arte joven. Hasta ese momento no se habían realizado en dicha institución exposiciones individuales de artistas argentinos: por 
ejemplo, un año atrás Romero Brest le había negado esa posibilidad a Alberto Greco, uno de los más revulsivos y relevantes artistas de la vanguardia sesentista. ${ }^{5}$ Resulta notable entonces que el primero que tuviera ese lugar fuera Berni, quien pocos años antes no hubiera sido siquiera considerado para formar parte del programa que sostenía la institución. El premio veneciano había venido a trastocar las posiciones del campo artístico local.

Así, en junio de 1965, bajo la nueva luz del reconocimiento internacional, se llevó a cabo en el CAV-ITDT una retrospectiva de Berni, donde se presentó un vasto conjunto integrado por pinturas, collages, grabados, construcciones y matrices de impresión. ${ }^{6}$ Las propias obras eran los elementos probatorios que sostenían, en palabras de Romero Brest, el "caso Berni" : desde su texto de presentación -aquél que se mencionara al inicio de este artículo-, el crítico daba cuenta del deslumbrante cambio en la producción del artista desde su época de "neorrealismo socialista" hasta las series de Juanito y Ramona. Aludiendo en su texto de presentación a las obras últimas de Berni como punto destacado de la muestra, Romero Brest privilegiaba esta faceta de su producción -la reconocida en términos internacionales- por sobre las anteriores : el Di Tella confirmaba en el plano local lo que había sido consagrado en el internacional.

17 Junto a algunas de las grandes obras históricas de Berni de la década del treinta, como Desocupación o Chacareros, sus construcciones polimatéricas -conocidas luego como "los monstruos de las pesadillas de Ramona"- conformaron uno de los puntos más sobresalientes de la muestra: más allá de su impacto visual, se trataba de una obra inédita, lo más nuevo de la nueva producción de Berni. Junto a este conjunto de construcciones tridimensionales se desplegaba otro grupo de obras novedosas : su nueva serie de grabados. "Berni is at his best in the engravings", ${ }^{7}$ señalaba una crítica para dar cuenta de sus estampas xilográficas con collage y relieve donde, junto al volumen progresivo de las impresiones, se destacaba el trabajo decorativo u ornamental con los objetos pegados sobre la matriz o moldeados con yeso piedra, como en El Obispo o en Ramona en el show. Otros xilocollages sobre Ramona y sus nuevos amigos, como El matador o El picador, se presentaban en las salas de la calle Florida por detrás del emblemático lienzo Manifestación de 1934.

18 La ponderación de la figuración de estas obras, más allá de los recursos técnicos, era uno de los ejes que atravesaba las lecturas locales : la centralidad del discurso narrativo era un rasgo de la obra de Berni que se afianzaba con este conjunto. En Primera Plana, el principal medio gráfico que propagaba el imaginario modernizador en los sesenta, se sostenía que "uno de los artistas más originales y profundos que ha producido el país, ha logrado conjugar las más actuales técnicas del collage y el cosismo con la fidelidad a los principios del realismo social que siempre informaron su obra. La consagración internacional le valió, por lo demás, el levantamiento de una suerte de ostracismo en que la crítica lo mantuvo durante casi 20 años." 8

19 La exposición constituyó un éxito de público : de las muestras realizadas por el CAV en ese año, fue la que tuvo más asistentes y, dentro de su historia, fue la tercera más visitada, luego de las muestras de Julio Le Parc y de Pablo Picasso en $1966 .{ }^{9}$ La medición cuantitativa del público implicaba entonces un aval para confirmar aquello legitimado inicialmente por la selección institucional y la premiación internacional. El impacto del premio en la Biennale se había sentido en la institución de la calle Florida y así, el centro de la joven vanguardia artística local de los años sesenta reconfirmaba a Berni, un artista de sesenta años, que celebraba una de las más exitosas muestras en la historia del Di Tella. 
En esa exposición retrospectiva se daba cuenta, tres años después de la consagración en Venecia, que el innovador grabado del viejo pintor ya era un nuevo clásico del arte argentino contemporáneo.

Antonio Berni puede ser figura familiar en los grandes salones de Francia, de Italia y de EE.UU. Puede tener una trayectoria rioplatense, seguida muy de cerca por la crítica especializada. Puede tener la consagración de un gran Premio en la Bienal de Venecia, distinción raramente alcanzada por un americano. Pese a ello su nombre dice muy poco al aficionado nuestro. Por eso tiene importancia su presencia en IGE, como divulgación de uno de los valores más nobles de la plástica argentina, tan poco conocida aquí. ${ }^{10}$

Como venía sucediendo desde su consagración en Venecia, 1966 también fue un año prolífico para Berni en términos de la circulación internacional de su producción. Las obras que en general se presentaban en sus distintas muestras individuales o en las colectivas donde participaba eran estampas: nuevas escenas de la vida de Ramona. Imágenes potentes, inéditas, atractivas; imágenes impresas sobre papel, múltiples y fáciles de trasladar. En relación con estas posibilidades, a la mayor movilidad que posibilita la obra gráfica hay que agregar las mejores condiciones legales imperantes desde 1963, ya que desde ese momento un decreto había exceptuado a las obras de arte de los derechos aduaneros argentinos (PLANTE, 2013: 247). Los grabados múltiples podían también entonces amplificar sus horizontes de circulación.

El año se iniciaba para Berni con el saluto que Mario de Micheli (1966) le dedicara para su primera muestra individual en Italia, consistente en cuarenta y cinco grabados realizados en los últimos tres años y presentados en la romana Galeria Due Mondi. Sosteniendo que el corpus presentado en Venecia en 1962 había sido "come un frutto fuori stagione, maturato in anticipo", planteaba que "si capiva benissimo che dietro le tue opere c'era un'artista 'esperto', che aveva vissuto le esperienze dell'arte contemporanea, dal postcubismo al surrealismo, in modo diretto, qui, in Europa, ma era anche evidente con quanta liberta ogni 'dato' si fosse ormai attivamente sciolto in una larga e prepotente vena epico-popolare, in una generosa espressione dei sentimenti e dell'imaginazione plastica". ${ }^{11}$ Cabe señalar que, meses después, estas mismas palabras serían retomadas, en su versión castellana y sin atribución de autoría, en una de las notas de prensa sobre la muestra de Berni en Montevideo. ${ }^{12}$

La Galerie L'oeil écoute de Paris fue otro de los escenarios para la difusión de los grabados de Berni cuando, en mayo de ese mismo año, se presentaron también allí sus Ramonas de papel. Calificada como una "exposition extraordinaire", se destacaba su "monde étrange et baroque style, oscillant du classicisme au surréalisme." 13

En este derrotero internacional, el miércoles 15 de junio de 1966 se inauguró una muestra individual de Berni en las salas del IGE de Montevideo. ${ }^{14} \mathrm{~A}$ pesar de la cercanía geográfica con Buenos Aires, su ciudad de residencia, hacía 28 años que Berni no presentaba su obra en la capital uruguaya: la anterior -y, en realidad, única- vez que expusiera allí había sido en ocasión de la muestra óleos y témperas del pintor argentino Antonio Berni en la sede de Amigos del Arte de Montevideo, en 1938. Pero la coyuntura y el escenario institucional de los sesenta resultaba bien diferente del de décadas anteriores y, en este sentido, el IGE tenía un rol central.

24 Tal como sostuvo Gabriel Peluffo Linari, el IGE significó un espacio simbólico de la modernidad que vino a alterar el tradicional campo cultural montevideano, una "burbuja" llamada a ser el principal centro de difusión de los nuevos valores de las artes 
plásticas en el Uruguay de los años sesenta, particularmente de la pintura. Sostenido por el mecenazgo industrial, "el poder de convocatoria y difusión asumido por el IGE, ofrecía ciertas esperanzas de solución a esa insoslayable contradicción entre la experimentación iconoclasta y la pretensión de ganar, en esa aventura, al gran público para un arte de élite". (PELUFFO LINARI, 1997 : 125). Ángel Kalenberg, director del IGE, sostenía como programa institucional el "mantener el signo de la contemporaneidad", tal como declaraba en Buenos Aires en una entrevista publicada en Primera Plana el 20 de julio de 1965, pocos días después de la finalización de la retrospectiva de Berni en el ITDT.

El IGE se creó en 1963 ; en ese mismo año, como ya se ha mencionado, se inauguraban las salas del CAV-ITDT en la calle Florida. También el cierre de ambos proyectos institucionales, en el año 1969, resulta sincrónico. ${ }^{15}$ Pero no fue sólo esta coincidencia cronológica la que vincula a ambas instituciones. Partiendo de electrodomésticos y automotores, la clave de la modernización cultural vinculaba aI IGE y al ITDT. Ambas instituciones tenían varios puntos en común: la inscripción de sus actividades como parte de un programa de mecenazgo industrial y con apoyo de capitales norteamericanos ; su contribución a la formación de un nuevo público conformado en su mayoría por sectores medios y universitarios, su apoyo a los nuevos artistas locales, su impulso a la exploración de soportes, tecnologías y poéticas. Operando desde escalas de intervención y estructuras diferenciadas (PELUFFO LINARI, 1997: 114), la referencia para Kalenberg era el "cercano esplendor" del ITDT.

26 A estos indicadores generales se deben agregar también algunas referencias particulares o, más bien, anclajes personales: la presencia en el IGE de algunos nombres vinculados al ITDT, como la presentación en 1967-1968 de pinturas de Rómulo Macció y Jorge de la Vega, instalaciones de Julio Le Parc, obras de Nicolás García Uriburu, es decir, artistas fuertemente vinculados al programa del ITDT y de las selecciones de Jorge Romero Brest en distintos momentos de esa década. También, en 1965, Samuel Paz -mano derecha del director del CAV- fue jurado en el Segundo Salón de Pintura Moderna de la institución uruguaya.

Así, en 1966, un año después de la exitosa retrospectiva de Berni en el ITDT, se presentó su obra en el IGE. Precisamente a instancias de la muestra del artista argentino, la prensa la destacaba "como una institución promotora de la cultura contemporánea [que...] ha servido para promover y difundir los valores en su nivel selectivo de elevadas exigencias centrado en lo contemporáneo". ${ }^{16} \mathrm{Si}$ el IGE sostenía un programa cultural modernizador, Berni resultaba para esos tiempos uno de los principales exponentes del arte destacado en la escena contemporánea.

Es notable que en las numerosas reseñas o comentarios sobre la muestra publicadas en la prensa montevideana, donde primaron los datos biográficos del artista, no se incluyera la referencia a la retrospectiva porteña como antecedente inmediato. En una de las notas donde se incluían más detalles sobre su biografía -con datos específicos sobre sus muestras individuales como la de 1938 en Amigos del Arte de Montevideo, la de 1955 en la Galeria Creuze en Paris, la de 1963 en la Galerie du Passeur, de Grabados en el Museo de Arte Moderno de Miami, en la Henry Gallery de Alejandria o la retrospectiva en el Museo de Arte Moderno de Santiago de Chile en 1964- no se mencionaba la muestra en el Di Tella de "Antonio Berni, del que el uruguayo más distraído del quehacer plástico que haya ido a Buenos Aires conoce por lo menos su mural en la Galería Pacífico." ${ }^{17}$ reiteración más que por omisión- fue la reproducción de una foto de Berni observando 
una estampa de la tirada de Ramona en el show. A diferencia de la muestra abarcativa en el ITDT, la obra presentada en el IGE fue exclusivamente gráfica: esa misma producción impresa múltiple que circulaba por esos años en distintos espacios de exhibición.

Ramona en el Music Hall, Ramona en la intimidad, Ramona bailarina, Ramona adolescente, En la calle, Bataclana, En el show, El torero, El Picador, El Matador, El Obispo, El religioso griego y El religioso armenio fueron algunas de las obras presentadas en el IGE. Este corpus formaba parte de la tirada de estampas presentadas en el ITDT, en Due Mondi, en L'oeil écoute y demás espacios contemporáneos. Más abigarrada y ornamental que el primer conjunto de Ramona et ses amies presentados en la Galerie du Passeur de Paris y en el MAM de Buenos Aires en 1963, Berni retomaba en esta serie distintos momentos de la vida de Ramona a la vez que introducía nuevos "amigos", esta vez ya no sólo ligados al poder -como los religiosos y obispos- sino también al propio placer de la muchacha: los personajes vinculados a la tauromaquia, tópico que se asocia en términos temáticos con el canónico corpus gráfico goyesco y picassiano. A la vez, proseguía aquí con la técnica del xilocollage-relieve ya inaugurada en la serie de grabados de 1963, aunque en este caso con estampas de menor tamaño, más centrado en la exploración de los efectos del relieve del papel y en la inclusión de diversos elementos ornamentales para la construcción de los vistosos ropajes de los personajes. Precisamente, la técnica de estas estampas fue uno de los principales focos de la prensa en relación con la recepción de la muestra:

31 En la incisión misma del trabajo es dable observar cómo Berni emplea un verdadero bordado de líneas y cómo ciertos patrones decorativos los aplica con una intuición manifiesta. En lo que respecta a la imprimación, es también creación para el artista. El empleo de monedas, botones, relieves logrados por presión sobre elementos ya en la matriz o superpuestos, le han facilitado la interpretación de esta fastuosa mujer llamada "Ramona".

Las aplicaciones no son de "collages" sino que existen en los preparativos previos a todo un manejo de elementos comunes y humildes que coadyuvan en el trabajo creativo del grabador. Los relieves son de mucha incisión; a veces llegan a más del centímetro fuera de la superficie. Este modelado que fue tan peculiar en Berni pintor, se ve ahora salir por gravitación e imposición de una soberana función de sensación de la forma. ${ }^{18}$

Por su parte, en Marcha se retomaba la lectura sobre la experimentación técnica del artista aunque desde una lectura crítica que incluía un matiz cuestionador:

Desde que Antonio Berni expuso en Venecia sus obras populistas su lenguaje se ha popularizado aunque su arte no sea popular. [...las xilografías de Juanito Laguna] dudo que permitan la reproducción infinita e idéntica que debiera ser condición para considerar a las obras como grabados en sentido estricto. De todos modos, me parece inconducente poner énfasis en el puro procedimiento [...] En cambio resulta sugerente considerar que Berni, también en aquello que es "cocina" ha pretendido innovar. En esto acompaña al tenaz movimiento de reacción, característico de los artistas actuales de entidad, contra todo lo convencionalmente aceptado. [...]

Berni, parece obvio, se ha plantado ante xilografías, litografías, serigrafías, aguatintas, puntas secas y aguafuertes con la actitud del iconoclasta y ha podido dar a luz un procedimiento que es tan nuevo como él quisiera que fueran conceptualmente sus obras. [...] Berni, laureado y seguido, es un representante del abigarrado arte oficial, que cuenta precisamente entre sus proclamas la que exige cambiar de recetas cada temporada. Así las cosas, no se sabe dónde está la verdadera, la sana revolución artística. ${ }^{19}$ 

las notas de prensa en las que el artista argentino era presentado como un "deslumbrante creador de imágenes", un "atento experimentador de los medios visuales". ${ }^{20}$ En tiempos del auge de la imagen gráfica -que en el Uruguay, al igual que en el resto del mundo occidental, asistió a un momento de inédita visibilidad- (PELUFFO, 1998) la obra de Berni resultaba sorprendente e impactante. Sin dudas, sus xilocollage-relieve resultaban distintos de la tradición del grabado local, con fuerte desarrollo en el uso más ortodoxo de la xilografía. Como señalaba un cronista de la época, la exposición en el IGE mostraba "una faceta artesanal de este artista no conocida aquí ni realizada en este estilo por otros grabadores". ${ }^{21}$ continua y prolongada actuación lo largo de varias décadas en la que se destacó la labor de Leonilda González, Adela Caballero, Carlos Fosatti, Miguel Bresciano, Gladys Afamado y Luis Mazzey, entre otros (TISCORNIA, 2011 ; PELUFFO, 2013). ${ }^{22}$ Aunque su programa de difusión del arte impreso se desarrolló en particular en el contexto del campo cultural local, el Club de Grabado de Montevideo estableció algunos contactos con agrupaciones similares ; tal fue el caso del Club de la Estampa de Buenos Aires, donde expusieron varios de los xilógrafos uruguayos en mayo de 1966. Cabe mencionar que, aunque Berni nunca fue socio del Club de la Estampa, sí participó de la muestra inaugural de la agrupación, en octubre de 1965 ; sin embargo, su producción se encontraba alejada de las obras más ortodoxas de la mayoría de los miembros de la agrupación porteña y de la montevideana.

de Berni también resultaba distante de otras propuestas locales que abrevaban en técnicas gráficas contemporáneas, como las obras incluidas en la carpeta de serigrafías impresas por Raúl Pavlotzky que, a fines de 1964, inició el IGE como modo de difundir -en forma seriada pero limitada- la obra de varios artistas uruguayos asociados en su mayoría a las poéticas informalistas y a la nueva figuración en boga (PELUFFO LINARI, 1997: 121).

En el marco de las aperturas y exploraciones de nuevas técnicas, materiales y poéticas sostenidas en el campo montevideano y particularmente desde el programa del IGE de esos años, la muestra de Berni fue así destacada por la prensa por su dimensión de renovación gráfica. ${ }^{23} \mathrm{~A}$ la vez, el registro desde las páginas de $B P$ color resulta interesante para poner en relieve otro aspecto sobre esta obra que subyacía en las lecturas contemporáneas: la cuestión del estatuto artístico híbrido de la producción impresa. El 15 de junio se sostenía que:

El artista rosarino lleva ya más de 30 años trajinando y renovando su arte, hasta llegar a esta artesanía superior [...]. Hemos visto muchos de esos grabados donde el sentido comercial se eleva en creación estética muy particular. Las figuras tienen una dimensión en relieve, un repujado en papel Walman realizado unas veces en seco y otras entintado, incluso en color, con verdadero carácter de divulgación artística. [...] De cada uno de sus trabajos, el grabador hace una tirada limitada y numerada con la cual cumple su intención divulgadora de la creación artística. Ha resuelto así una forma válida de artista comerciante. ${ }^{24}$

Dos días después, el mismo cronista volvía a referir a esta muestra como "original y orgánica" y, respecto de los grabados, ampliaba:

Quizás alguno piense que estas reproducciones de grabados, a nivel original, sea una muestra "menor" de la obra de Berni, pero esta consideración se borra no bien el visitante recorre el esplendor de la muestra. 
De entrada recibe tal impacto, que lo incita al diálogo y a la reflexión. Esas láminas con prominentes relieves, o profundas hendiduras tan artísticamente logradas sobre el papel, le van mostrando una historia, dramática y humana, transfigurada por el talento de un artesano que revela conocimiento, experiencia e imaginación. ${ }^{25}$

Basándose, probablemente, en la condición de factura manual detallada, meticulosa, preciosista que requería la realización de la matriz y la impresión de este tipo de obra gráfica, el cronista aludía a la, ya por entonces antigua, división entre "arte" y "artesanía", a la vez que implicaba algunas tensiones e indefiniciones entre el "grabado artístico" y la reproducción (DOLINKO 2003; 2009 a ; 2009 b). La noción de "lámina" -más vinculada con la industria de la impresión fotomecánica- introducía en esta lectura una cuota de imprecisión o, mejor dicho, de ambigüedad. A la vez, la nota mencionaba a estas estampas de xilocollage-relieve en tanto "reproducciones de grabados", dando cuenta de una interpretación opuesta a la de la noción de grabado original en tanto obra de arte inherentemente multiejemplar. Es evidente que la idea de un arte seriado resultaba aún por esos años imprecisa y compleja, por lo que uno de los puntos discutibles de las notas de $B P$ color radicara en esta confusión entre obra multioriginal propia de la estampa artística que se presentaba en las salas del IGE, y la de impresión fotomecánica.

Las imágenes gráficas de Berni pivotaron entre ambos polos de producción. Así, junto a las distintas series y tiradas de xilocollage-relieve sobre Ramona que surgían directamente de la prensa del taller del artista, en 1966 se publicó a través de Ediciones El Mate un álbum con las imágenes de estas estampas sobre el personaje (SABATO y SCHÓO, 1966). Se trataba de la saga de Ramona en España, con los picadores, toreros, religiosos y demás personajes de esa secuencia ya consignada. Las imágenes que integraban el álbum tenían muy buena calidad de resolución gráfica pero sin el relieve ni las texturas táctiles que caracterizan a las estampas originales. Se trataba, aquí sí, de reproducciones.

Los ejemplares de esta carpeta se habían puesto en venta ese año en el marco de la muestra de Berni en la Galería de las Artes (Córdoba 947, Buenos Aires), ${ }^{26}$ y sin dudas también debieron circular por Montevideo. Fueron estas mismas imágenes de Ramona incluidas en el álbum editado por El mate las presentadas en el IGE. Pero, en ese caso, se trató de las estampas originales, en su tirada "limitada y numerada", tal como señalaban las palabras de Aprendiz; sin embargo, la reseña se prestaba a confusión en su superposición de las nociones de original, impreso, reproducción y divulgación.

6 Se puede presuponer que la alusión en la reseña de BP color a Berni como "artista comerciante" -enfáticamente cuestionada por Gerardo Ipar "amigo, admirador y en cierto modo gestor oficioso del artista"- ${ }^{27}$ y a su "intención divulgadora de la creación artística" se fundara en la multiejemplaridad del grabado, aunque también podría radicar en la confusión entre las estampas de tirada limitada y el álbum de circulación comercial más accesible en términos económicos : así, la expansión de las formas de lo impreso que se suscitaba por aquellos años implicaba, también, a esos mismos sectores medios que asistían tanto al ITDT en Buenos Aires como al IGE en Montevideo.

Las Ramonas impresas y múltiples circulaban entonces en distintos escenarios: en las dos instituciones más paradigmáticas de la modernización cultural rioplatense de la década, y también en diversos espacios europeos; no sólo en galerías y museos, sino también en el circuito de bienales que comenzaba a extenderse en el mapa de la escena artística internacional (WOIMANT, 1972: 8-10). Así como un año antes, mientras que su obra se presentaba en las salas del ITDT Berni obtenía una de las distinciones en la VI Bienal 
Internacional de Grabado de Ljubljana, ${ }^{28}$ en agosto de 1966, a continuación de la muestra en IGE, otra de sus estampas de esa serie recibía uno de los premios en la I Bienal Internacional de Gráfica en Cracovia. ${ }^{29}$ Posibilidades de la multicirculación de los grabados que traían nuevos reconocimientos y la presencia en diversos escenarios al artista. En tiempos de programas de internacionalización del arte, su obra se mostraba como ejemplo de la "escuela nacional argentina" (CHEVALIER, 1964) : Berni se había convertido en el exponente más conocido y con mayor repercusión del nuevo grabado.

\section{BIBLIOGRAFÍA}

AMARAL Aracy, Arte para quê ? a preocupação social na arte brasileira 1930-1970 : subsídio para uma historia social da arte no Brasil, São Paulo, Studio Nobel, 2003.

AMIGo Roberto (ed.), Berni: narrativas argentinas, Buenos Aires, MNBA, 2010.

AMIGo Roberto, Dolinko Silvia y Rossi Cristina (eds.), Palabra de artista. Textos sobre arte argentino, 1961-1981, Buenos Aires, Fundación Espigas-Fondo Nacional de las Arte, 2010.

BUCCELLATo Laura, “Historia de dos personajes: Juanito Laguna y Ramona Montiel”, in Antonio Berni, Madrid, Telefónica de España - Fundación Arte y Tecnología, 1997.

CHEVALIER Denys, "Les grands bienales d'art 1963. La gravure internationale à Ljubljana”, in XX siècle, Paris, 1964, a. XXVI, n. 23.

DE MICHELI Mario, Saluto a Berni, Roma, Galeria Due Mondi, 1966.

DOLINKo Silvia, “Antonio Berni y la Bienal de Venecia de 1962: recepción de un premio internacional", in Terceras Jornadas Estudios e Investigaciones Europa/ Latinoamérica, Artes Plásticas y Música, Instituto de Teoría e Historia del Arte “Julio E. Payró", Facultad de Filosofía y Letras, Universidad de Buenos Aires, 1998.

DOLINKO Silvia, “Arte para todos", in La difusión del grabado como estrategia para la popularización del arte, Buenos Aires, Fundación Espigas, 2003.

DoLinko Silvia, "La Bienal de Venecia, o cómo tener un lugar en el mundo", en, Arte de posguerra. Jorge Romero Brest y la revista Ver y Estimar, Andrea GIUNTA y Laura MALOSETTI COSTA (comps.)Buenos Aires, Paidós, 2005.

DoLINKo Silvia, “Una oculta expresión: dos discursos de Jorge Romero Brest sobre Antonio Berni”, in Avances. Revista del Área Artes, Córdoba, Centro de Investigaciones de la Facultad de Filosofía y Humanidades, UNC, 2004.

DOLINKo Silvia, "El grabado, una producción híbrida como problema para el relato modernista", in Critica Cultural, Santa Catarina, Universidade do Sul de Santa Catarina (UNISUL), 2009 a, vol. 4, n. 1.

DOLINKO Silvia, "Grabados originales multiplicados en libros y revistas" in Impresiones porteñas. Imagen y palabra en la historia cultural de Buenos Aires, Laura MALOSETTI COSTA y Marcela GENÉ (dir.), Buenos Aires, Edhasa, 2009 b. 
DOLINKo Silvia, “Obra múltiple en la ampliación del consumo artístico”, in Travesías de la imagen. Historias de las artes visuales en la Argentina, María-Isabel BALDASARRE y Silvia DOLINKO (eds.), Buenos Aires, CAIA-Eduntref, 2011,vol. 1

DOLINKo Silvia, Arte plural. El grabado entre la tradición y la experimentación 1955-1973, Buenos Aires, Edhasa, 2012.

GASSIOT-TALABOt Gérald y Michel Troche, Berni, Paris, Editions Georges Fall, 1971.

GHEERBRANDT Bernard, “L'estampe est à la mode”, in XX' Siècle, Paris, a. 20, 1958, n. 10.

GHILIONI Emilio H. y TAVERNA IRIGOYEN Jorge M., Juan Grela G. Obra gráfica, Rosario, Laborde editorUNR editora- Humanidades y Artes ediciones, 2008.

GIUNTA Andrea, Vanguardia, internacionalismo y política. Arte argentino en los sesenta, Buenos Aires, Paidós, 2001.

GIUNTA Andrea, "Cita con la vanguardia. Imaginarios del arte argentino de los sesenta", in Arte y política, Santiago de Chile, Universidad Arcis, 2005.

KATZENSTEIN Inés y CIPPOLINI Rafael, Televisión. El Di Tella y un episodio en la historia de la TV, Buenos Aires, Fundación Telefónica, 2011.

KING John, El Di Tella y el desarrollo cultural argentino en la década del sesenta, Buenos Aires, Gaglianone, 1985.

LAURíA Adriana, “Correlatos entre Berni y sus contemporáneos”, in Berni y sus contemporáneos. Correlatos, Buenos Aires, Malba, 2005.

LONGONI Ana y MESTMAN Mariano, Del Di Tella a Tucumán arde. Vanguardia artística y política en el '68 argentino, Buenos Aires, Eudeba, 2010.

LÓPEZ ANAYA Jorge, Antonio Berni, Buenos Aires, Velox, 1997.

PACHECo Marcelo (ed.), Berni. Escritos y papeles privados, Buenos Aires, Temas, 1999, pp. 262-270.

PELUFFo LINARI Gabriel, "Instituto General Electric de Montevideo: medios masivos, poder transnacional y arte contemporáneo", in AA.VV., Cultura y política en los años '60, Buenos Aires, Oficina de publicaciones del CBC, 1997.

PELUFFo LINARI Gabriel, “El 'acto gráfico' de los sesenta”, in Dibujando los '60, Montevideo, Museo Municipal de Bellas Artes Juan Manuel Blanes, 1998.

PELUFfo LINARI Gabriel (dir.), Club de Grabado de Montevideo 1953-1993, Montevideo, Museo Juan Manuel Blanes, 2013.

PINTA María Fernanda, Teatro expandido en el Di Tella. La escena experimental argentina en los años 60, Buenos Aires, Biblios, 2013.

PLANTE Isabel, Argentinos de París. Arte y viajes culturales durante los años sesenta, Buenos Aires, Edhasa, 2013.

POLONI-SIMARD Jacques, “Antonio Berni. Les figures narratives, assemblées et gravées de Juanito Laguna, 'chico pobre de Buenos Aires', et de la prostituée Ramona Montiel”,in Nuevo Mundo Mundos Nuevos, Coloquios, http://nuevomundo.revues.org/66240, 2014.

RABOSSI Cecilia, “Antonio Berni cuenta la historia de Juanito Laguna”, in Antonio Berni. A 40 años del Premio de la XXXI Bienal de Venecia 1962-2002, Buenos Aires, Centro Cultural Recoleta, 2002. 
RAGON Michel, Antonio Berni peint en 20 tableaux le roman feuilleton de son nouveau personagge:

Ramona Montiel, Paris, Arts, 1962 a.

RAGON Michel, XXXI ${ }^{\underline{a}}$ Bienal de Venecia, Cimaise, 1962 b, n. 61.

Rossi Cristina (ed.), Antonio Berni. Lecturas en tiempo presente, Buenos Aires, Eudeba-Eduntref, 2010.

Tiscornia Ana (ed.), Club de Grabado de Montevideo, Montevideo, Centro Cultural de España, 2011.

SÁBATo Ernesto y schóo Ernesto, Antonio Berni: Ramona Montiel, Buenos Aires, Editorial El Mate,

1966.

VIÑALS José, Berni, Buenos Aires, Imagen Galería de Arte, 1976.

WOIMANT Françoise,“Bienales. Répertoire international”, Nouvelles de l'estampe, Paris, janvier 1972.

\section{NOTAS}

1. Reproducido también en "Exposiciones", Acción, Montevideo, 3 de julio de 1966. Archivo Berni, Fundación Espigas, Buenos Aires (en adelante, AB-FE). Todas las notas de prensa uruguaya citadas en este trabajo han sido consultadas en este repositorio documental.

2. Retomo en la primera parte de este trabajo algunos aspectos sobra la obra de Berni que ya he abordado en otras instancias para poder vincularlos aquí con la escena montevideana de los sesenta, privilegiando la lectura sobre este ámbito de la circulación de su obra no revisado hasta el momento.

3. Gassiot-Talabot (1971: 9)

4. Jorge Romero Brest, s/d, Archivo Jorge Romero Brest, Instituto de Teoría e Historia del Arte "Julio E. Payró", Facultad de Filosofía y Letras, Universidad de Buenos Aires, c4-s2-p. Mecanografiado, 2 pp.

5. Carta de Romero Brest a Alberto Greco, Buenos Aires, 23 de julio de 1964. Archivo JRB, c22s6-263.

6. Berni. Obras 1922-1965, Centro de Artes Visuales del Instituto Torcuato Di Tella, Buenos Aires, 18 de junio al 11 de julio de 1965.

7. "Monsters galore at Berni's one-man show", Buenos Aires Herald, Buenos Aires, 2 de julio de 1965.

8. 'La historia de una muchacha provinciana', Primera Plana, Buenos Aires, 6 de agosto de 1963, p. 26. Suerte de ostracismo, en realidad, de los medios más modernos como la revista Ver y Estimar, dirigida entre 1948 y 1955 por Romero Brest.

9. De acuerdo a los datos consignados en las Memorias del Instituto Di Tella, a la exposición de Berni asistieron 40.892 personas, cuando ese mismo año también se registraron 33.694 asistentes a la exposición de Jean Dubuffet y similar cantidad a La Menesunda, 18.656 al Premio Nacional del ITDT y 20.106 al Premio Internacional. A la exposición de Le Parc, 159.287 personas y a la de Picasso, 113.201 personas. 1965/1966. Memoria y balance. Instituto Torcuato Di Tella, p. 15.

10. Aprendiz, "Originales grabados de Antonio Berni”, BP Color, Montevideo, 17 de junio de 1966.

11. La galería también vendía obras de Demetrio Urruchúa, Oswaldo Guayasamín, Juan Carlos Castagnino, José Echave, entre otros artistas latinoamericanos.

12. “Antonio Berni expone hoy en los Salones del I.G.E.”, El País, Montevideo, 15 de junio de 1966.

13. André Mure, "Berni et sa Ramone”, Resonances, Lyon, juin 1966.

14. La fecha de inauguración de mediados de junio se vincula con la del otorgamiento del premio en la Bienal de Venecia, y también con la de la apertura de la muestra en el ITDT del año anterior. 15. En realidad, el CAV-ITDT cerró formalmente sus puertas a mediados del año 1970, pero en términos efectivos, sus actividades y programación cesaron a finales de 1969. 
16. “Antonio Berni expondrá desde hoy en el Instituto General Electric", El debate, Montevideo, 14 de junio de 1966

17. “Berni 28 años después”, Acción, Montevideo, 14 de junio de 1966. Véase también "Grabador argentino de renombre, expone en el IGE”, El país, 23 de junio de 1966 o “Antonio Berni expondrá desde hoy...", op. cit.

18. "Antonio Berni y la historia grabada del motivo 'Ramona", El día, Montevideo, 16 de junio de 1966.

19. Pablo Mañe Garzón, "Berni : del populismo al rococó”, Marcha, Montevideo, 1 de julio de 1966. 20. “Antonio Berni, hombre de recursos”, Época, Montevideo, 25 de junio de 1966.

21. Aprendiz, “Originales grabados de Antonio Berni”, B.P.Color, Montevideo, 17 de junio de 1966. Distinto era el caso de su presencia en Buenos Aires ya que, si bien con resultados distintos, varios artistas experimentaban con el grabado desde fines de los años cincuenta, como Luis Seoane con la xilografía con collage o Fernando López Anaya con el gofrado y las poéticas del papel.

22. Con fuertes vinculaciones con el PC y la impronta del Taller de Gráfica Popular (TGP) mexicana, el Club de Grabado montevideano se inició en 1953, a instancias del contacto con los colegas brasileños del club de gravura de Rio Grande do Sul. Sobre los clubes de gravura, cf. AMARAL (2003).

23. Cabe aclarar que, hasta el momento, no se ha podido acceder a documentos o testimonios que permitan reconstruir y analizar las reacciones de los artistas uruguayos contemporáneos a la exposición Berni de 1966.

24. Aprendiz, "Los grabados de Berni en General Electric", B.P.color, Montevideo, 15 de junio de 1966.

25. Aprendiz, "Originales grabados de Antonio Berni", BPColor, Montevideo, 17 de junio de 1966. El destacado es mío.

26. “Grabados de Berni”, La Nación, Buenos Aires, 22 de marzo de 1966.

27. Aprendiz, "Más allá de la crónica y la muestra de A. Berni", en BP Color, Montevideo, 29 de junio de 1966. Sobre el cuestionamiento a la definición de "artesano" para la labor de Berni, véase "Charlas de café", Bicolor, Montevideo, 20 de junio de 1966.

28. "Nuevo galardón para Antonio Berni. Su obra 'El Matador', premiada en Yugoslavia”, Clarín, Buenos Aires, 11 de julio de 1965.

29. “Berni”, Clarín, 11 de agosto de 1966 y “Premio a Berni”, La Nación, 11 de agosto de 1966.

\section{RESÚMENES}

Este artículo se propone dar cuenta de la circulación del grabado de Antonio Berni, centrándose en el caso de su presentación en el Instituto General Electric de Montevideo y su vinculación con el Instituto Di Tella de Buenos Aires. Se apunta así a dar cuenta de la inscripción de la obra Berni en la trama cultural modernizadora rioplatense de los años sesenta, sosteniendo que la inclusión de las exposiciones del maduro y consagrado artista en estas instituciones asociadas a la vanguardia joven introducía un matiz particular en el programa de ambos espacios. Se brindaba así una especial visibilidad a las exploraciones contemporáneas de Berni con el xilocollagerelieve que, en el caso de la exposición montevideana, implicaba una marcada diferencia respecto de las tradiciones gráficas locales. 
Cet article a pour but d'analyser la circulation du travail graphique d'Antonio Berni, tout en focalisant sur sa présentation qui en fut faite à l'Instituto General Electric à Montevideo et ses liens avec l'Instituto Torcuato di Tella de Buenos Aires. L'objectif est de signaler la place de l'œuvre de Berni dans le contexte de la culture modernisatrice du Río de la Plata pendant les années 1960 : on soutiendra que la programmation d'un artiste consacré - et d'œuvres de sa période de maturité - dans des institutions liées à la nouvelle avant-garde modifiait l'image de ces deux espaces. Une visibilité concrète était offerte aux expérimentations de l'œuvre de Berni à cette époque, en particulier ses xylo-collages qui, dans le cas de l'exposition à Montevideo, se différenciaient nettement des traditions graphiques locales.

ÍNDICE

Palabras claves: Antonio Berni, ITDT, IGE, grabado, circulación, relaciones, Argentina, Uruguay Mots-clés: Antonio Berni, Años 1960, Gravure, Circulation, ITDT, relations, Argentine, Uruguay

\section{AUTOR}

\section{SILVIA DOLINKO}

Silvia Dolinko es doctora en Historia del Arte por la Universidad de Buenos Aires. Investigadora del Conicet, especializada en el estudio de obra gráfica del siglo XX. Profesora titular de Historia del Arte Argentino y Americano del siglo XX en el Instituto de Altos Estudios Sociales de la Universidad Nacional de San Martín y docente de Metodología de la Investigación en la FFyLUBA.

Conicet-UBA-IDAES/UNSAM. Email: silviadolinko[at]gmail.com 